\title{
A rare case of post radiation urinary bladder necrosis in a patient with carcinoma cervix
}

\author{
Karthikesh Omkaram ${ }^{1}$, Mallikarjuna Reddy Nalabolu², Ershad Hussain Galeti ${ }^{3}$, Vedamurthy Reddy ${ }^{3}$, Bhanu Teja Reddy ${ }^{2}$, \\ Ayesha Galeti $^{4}$
}

Cite this article: Omkaram K, Nalabolu MR, Galeti EH, Reddy V, Reddy BT, Galeti A: A rare case of post radiation urinary bladder necrosis in a patient with carcinoma cervix. Ann Urol Oncol 2021; 4(2): 56-61. https://doi.org/10.32948/ auo.2021.12.31

\begin{abstract}
In contrast to proctitis, vaginitis and acute radiation cystitis, late urological complications after pelvic irradiation are rarer, more serious and irreversible. The main disadvantage of radiotherapy is the fact that it affects both cancer and healthy cells located in the tumour area. As a consequence, different complications develop. A large proportion of cancers treated with radiotherapy are located in the lower abdomen and pelvis, which is why complications often involve the urinary tract. Due to the anatomy of these areas, urological complications occur not only after radiological treatment of urological cancers, but also after treatment of malignancies of the reproductive or digestive system. The most common radiation-induced complications include haemorrhagic cystitis, urethral and ureteral strictures, urinary fistulae, and secondary primary malignancies. Because of impaired tissue healing, the treatment of radiation urological complications is a challenge for urologists and often requires complicated reconstruction techniques. We hereby described an elderly woman who is a known case of carcinoma of cervix with post radical hysterectomy and post pelvic radiotherapy status presented with fever, pain abdomen, vomiting, obstipation, voiding difficulties with dysuria on admission, which was diagnosed as acute intestinal obstruction with post radiation bladder necrosis with acute kidney injury. This case is a rare example of high-grade late adverse events which occurred 8 yrs after radiation therapy in a known case of carcinoma of cervix.
\end{abstract}

Key words Radiotherapy; urological complications; pelvic malignancy; radiation cystitis

1. Department of Urology, Sri Srinivasa Kidney Centre, Hnamkonda,Telangana, India.

2. Department of Urology, CITIZENS Hospital, Hyderabad, India.

3. Department of urology, Narayana medical college, Nellore, Andhra Pradesh, India.

4. Department of Pathology, Narayana medical college, Nellore, Andhra Pradesh, India.

Correspondence: Ershad Hussain Galeti (Narayana medical college, Nellore, Andhra Pradesh, India; Email: dr.ershadhussain@gmail.com). 


\section{Introduction}

Cancers arising in the pelvis account for up to $18 \%$ of all cancers [1]. Radiation therapy (RT) has been utilized in the treatment of these cancers for more than 100 years [2]. Due to their anatomical location, the lower ureters, bladder and posterior urethra are exposed to radiation during treatment for pelvic cancers, giving rise to a variety of urinary adverse effects (AEs) [1]. Although serious complications occurred with early forms of RT, technological advancement in the delivery of RT has significantly reduced the AEs. Short-term AEs of RT are well described and generally well tolerated. Although the long-term urinary AEs of pelvic RT can be severe, they are thought to be rare; but long-term data are lacking [3].

We describe a case of an elderly woman who is a known case of carcinoma of the cervix with post Radical hysterectomy and post pelvic radiotherapy status presented with fever, pain abdomen, vomiting, obstipation, voiding difficulties with dysuria on admission, which was diagnosed as acute intestinal obstruction with post-radiation bladder necrosis with acute kidney injury (AKI). This case is a rare example of high-grade AEs which occurred 8 yrs after RT in a known case of carcinoma of the cervix.

\section{Case presentation}

A 54-year-old woman was referred to the emergency department with a chief complaint of pain in the abdomen from the past 5 days. History of fever with multiple episodes of vomiting, obstipation, burning micturition with decreased urine output since 3 days. The patient's history suggested that she is a known case of carcinoma of the cervix for which radical hysterectomy with 25 cycles of adjuvant pelvic radiation therapy was done 8 yrs back. History of Type II diabetes mellitus on insulin medication since 14 years. On presentation to the emergency department, she was conscious, oriented and was afebrile. Physical examination revealed pallor with no icterus/cyanosis/clubbing/lymphadenopathy. Blood pressure was $90 / 70 \mathrm{~mm}$ of $\mathrm{Hg}$ and pulse rate was $110 / \mathrm{min}$. On abdominal examination, Abdomen was soft, tender, distended with absent bowel sounds. On DRE, the rectum was loaded with hard petty stool. Her blood investigations revealed haemoglobin of $7.8 \mathrm{gm} / \mathrm{dl}$, TLC of 8600 cells $/ \mathrm{mm}$, serum urea of $128 \mathrm{mg} / \mathrm{dl}$, serum creatinine of $1.7 \mathrm{mg} / \mathrm{dl}$, serum electrolytes Na- $139 \mathrm{meq} /$

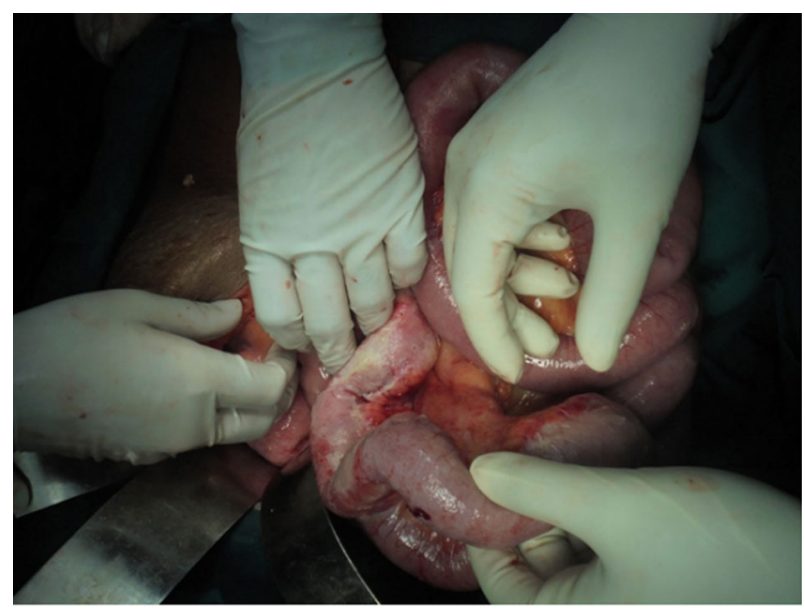

Figure 1. Distended small bowel loops with dense post-radiation adhesions leading to acute intestinal obstruction.
1, K- $4.8 \mathrm{meq} / \mathrm{l}, \mathrm{Cl}-98 \mathrm{meq} / 1$. Abdominal ultrasound showed distended small bowel loops with a maximum diameter measuring $4 \mathrm{cms}$ showing to and fro peristalsis with small partially distended bladder. X-ray of erect abdomen showed distended small bowel with multiple air-fluid levels s/o small bowel obstruction.

With a preemptive diagnosis of Small bowel obstruction, an exploratory laparotomy was done after stabilizing the patient with intravenous crystalloids and antibiotics. Intraoperative findings included dilated small bowel loops, dense adhesions between distal ileum and pelvic wall (Figure 1), $500 \mathrm{ml}$ toxic intraperitoneal fluid with complete bladder necrosis along with the bladder mucosa and transmural necrosis. Adhesiolysis with excision of the necrosed bladder wall (Figure 2 and 3) with drainage of toxic fluid and thorough saline wash of peritoneal cavity was done. As both small bowel and large bowel were unhealthy for urinary conduit creation because of post-radiation adverse effects, bilateral ureterostomies were done for urinary diversion (Figure 4 and 5).

Postoperatively the patient was kept in the intensive care unit on synchronized intermittent mandatory ventilation because of AKI with severe metabolic acidosis with respiratory distress with hypoxemia. The patient developed supraventricular tachycardia on POD3 which was managed with intravenous adenosine. Later the patient was extubated on POD5 with no respiratory distress. Over the next two days, her renal function tests (serum creatinine $-1.1 \mathrm{mg} / \mathrm{dl}$, serum urea $-48 \mathrm{mg} / \mathrm{dl}$ ) was normalized. The patient was discharged on POD 7 in a stable condition with bilateral ureterostomies in situ and after stoma care training (Figure 6). Histopathology of the necrosed bladder wall showed chronic radiation changes with fibrosis with no evidence of malignancy ( Figure 7).

Six months postoperatively, the Patient got readmitted and a transverse colon conduit (Figure 8) with bilateral ureteric reimplantation was done. On follow up, After one year patient is doing well with good stoma care with urine draining well through colostomy with improved quality of life. CECT abdomen showed good drainage of contrast into the sigmoid conduit with normal renal function ( Figure 9).

\section{Discussion}

Radiation is an effective cancer treatment due to its direct and indirect interaction with living cells. The direct interaction induces immediate cell death by damaging DNA and/or tissue protein.

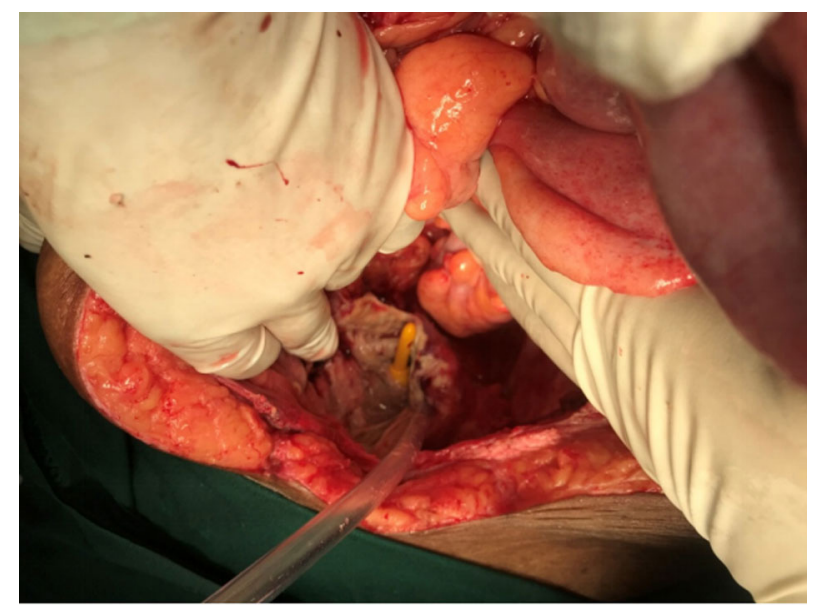

Figure 2. Picture showing complete necrosis of bladder with exposure of Foleys catheter. 


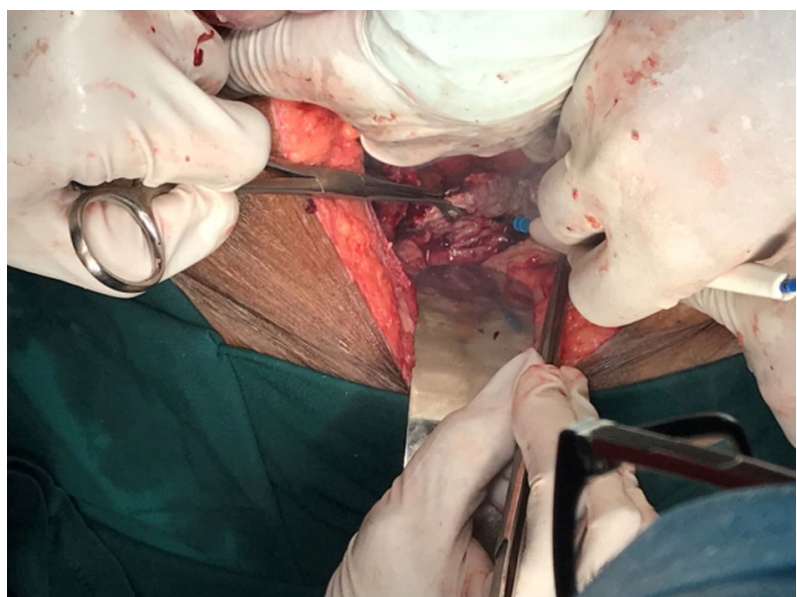

Figure 3. Excision of the necrosed bladder wall.

The indirect interaction occurs by the formation of free radicals by ionizing radiation that interacts with enzymes leading to cell death [4]. These direct and indirect interactions lead to cellular injury by affecting division delay, reproductive failure and interphase arrest. All these consequences are more frequently encountered in rapidly dividing cells [5].

A retrospective study of 10,709 patients reported late urological complications in 133 patients $(1.24 \%)$ after curative radiotherapy for gynecological malignancies, during an observation period of 22 years [6]. Bladder necrosis as a late complication of radiotherapy for cervical cancer has only been described thrice before [7].

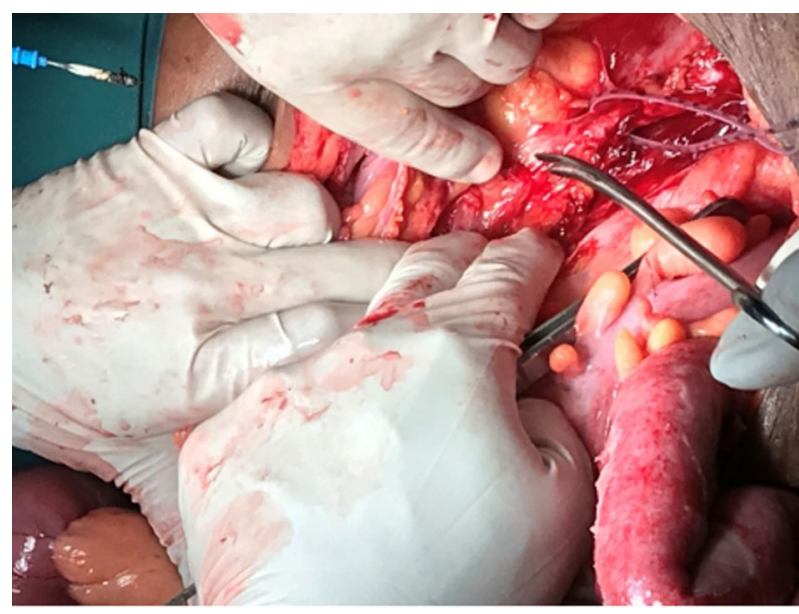

Figure 4. Dissection and isolation of left ureter.

Late urinary adverse effects (AEs) are usually graded using the Radiation Therapy Oncology Group (RTOG) system, which grades AEs on a scale of $0-5$. Grade 0 denotes no complications. Minor AEs like microscopic hematuria are labelled grade 1. Grade 2 AEs include moderate urinary frequency, generalized telangiectasia, or intermittent macroscopic hematuria. Grade 1 and 2 AEs are commonly managed with observation or medical therapy and have minimal impact on quality of life. Grade 3 and 4 AEs are considered severe. These are often managed with a procedure and have a significant impact on quality of life. Grade 3 AEs include

Table 1. Common terminology criteria for adverse events (CTCAE) version 4.0: A systematic grading system for AEs of cancer therapy and late $\mathrm{AE}$ as per RTOG.

\begin{tabular}{|c|c|c|c|}
\hline Grade & CTCAE & RTOG-Acute & RTOG-Chronic \\
\hline 0 & No change & No change & No change \\
\hline 1 & $\begin{array}{l}\text { Asymptomatic or mild symptoms; } \\
\text { clinical or diagnostic observations } \\
\text { only; intervention not indicated }\end{array}$ & - & $\begin{array}{c}\text { Slight epithelial atrophy, mild } \\
\text { telangiectasia (microscopic } \\
\text { hematuria) }\end{array}$ \\
\hline 2 & $\begin{array}{l}\text { Moderate, local or noninvasive } \\
\text { intervention indicated; limiting } \\
\text { instrumental activities of daily } \\
\text { living (ADL) }\end{array}$ & $\begin{array}{c}\text { Frequency of urination or nocturia less } \\
\text { frequent than every hour, dysuria, urgency } \\
\text { bladder spasm requiring local anaesthetic } \\
\text { (for example phenazopyridine } \\
\text { hydrochloride) }\end{array}$ & $\begin{array}{l}\text { Moderate frequency, generalized } \\
\text { telangiectasia, intermittent } \\
\text { macroscopic hematuria }\end{array}$ \\
\hline 3 & $\begin{array}{l}\text { Severe or medically significant but } \\
\text { not immediately life-threatening; } \\
\text { hospitalization or prolongation of } \\
\text { existing hospitalization indicated; } \\
\text { disabling; limiting self-care ADL }\end{array}$ & $\begin{array}{l}\text { The frequency with urgency and nocturia } \\
\text { hourly or more frequently, dysuria, pelvic } \\
\text { pain or bladder spasm requiring regular, } \\
\text { frequent narcotic, gross hematuria with or } \\
\text { without clot passage }\end{array}$ & $\begin{array}{l}\text { Severe frequency and dysuria, } \\
\text { severe generalized telangiectasia } \\
\text { (often with petechiae). Frequent } \\
\text { hematuria, reduction in bladder } \\
\text { capacity }(<150 \mathrm{cc})\end{array}$ \\
\hline 4 & $\begin{array}{l}\text { Life-threatening consequences; } \\
\text { urgent intervention indicated }\end{array}$ & $\begin{array}{l}\text { Hematuria requiring transfusion, acute } \\
\text { bladder obstruction not secondary to clot } \\
\text { passage, ulceration or necrosis }\end{array}$ & $\begin{array}{l}\text { Necrosis, contracted bladder } \\
\text { capacity }(<1,000 \mathrm{cc}), \text { severe } \\
\text { hemorrhagic Cystitis }\end{array}$ \\
\hline 5 & Death & Death & - \\
\hline
\end{tabular}




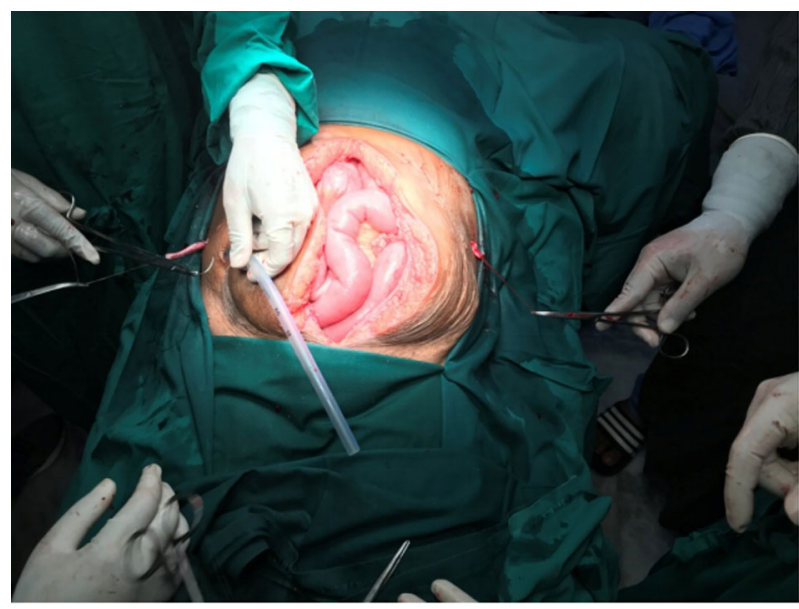

Figure 5. Creation of bilateral ureterostomies.

severe frequency or dysuria, severe generalized telangiectasia (often with petechiae), frequent hematuria, or a reduction in bladder capacity to less than $150 \mathrm{cc}$. Severe hemorrhagic cystitis, reduction in bladder capacity to less than $100 \mathrm{cc}$, and necrosis are classified as grade 4 . Our patient has grade 4 late urinary adverse effects as per the RTOG system. Any death resulting from late complications of radiation is considered grade 5 (Table 1).

While incidence rates of invasive cervical cancer in women aged 50 and older have been declining in recent years, rates have

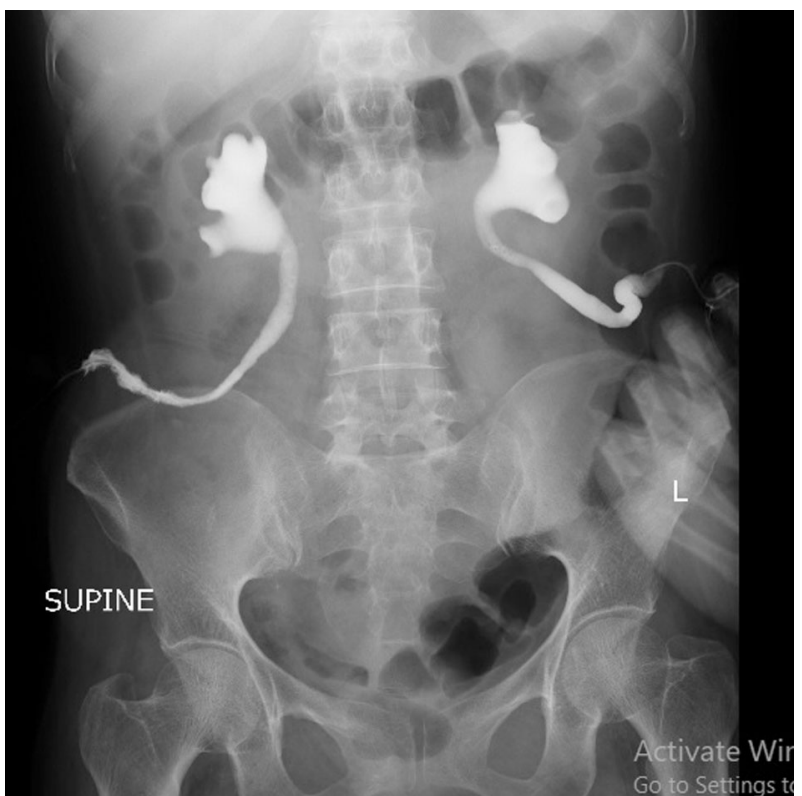

Figure 6. Postoperative Bilateral Ureterogram.

remained stable in women under 50, the latter group making up 59\% of new diagnoses [8]. While RT and radical surgery are equivalent in stage IB to IIA disease, RT is integral to the treatment regimen for stages IIB and greater. Adjuvant RT

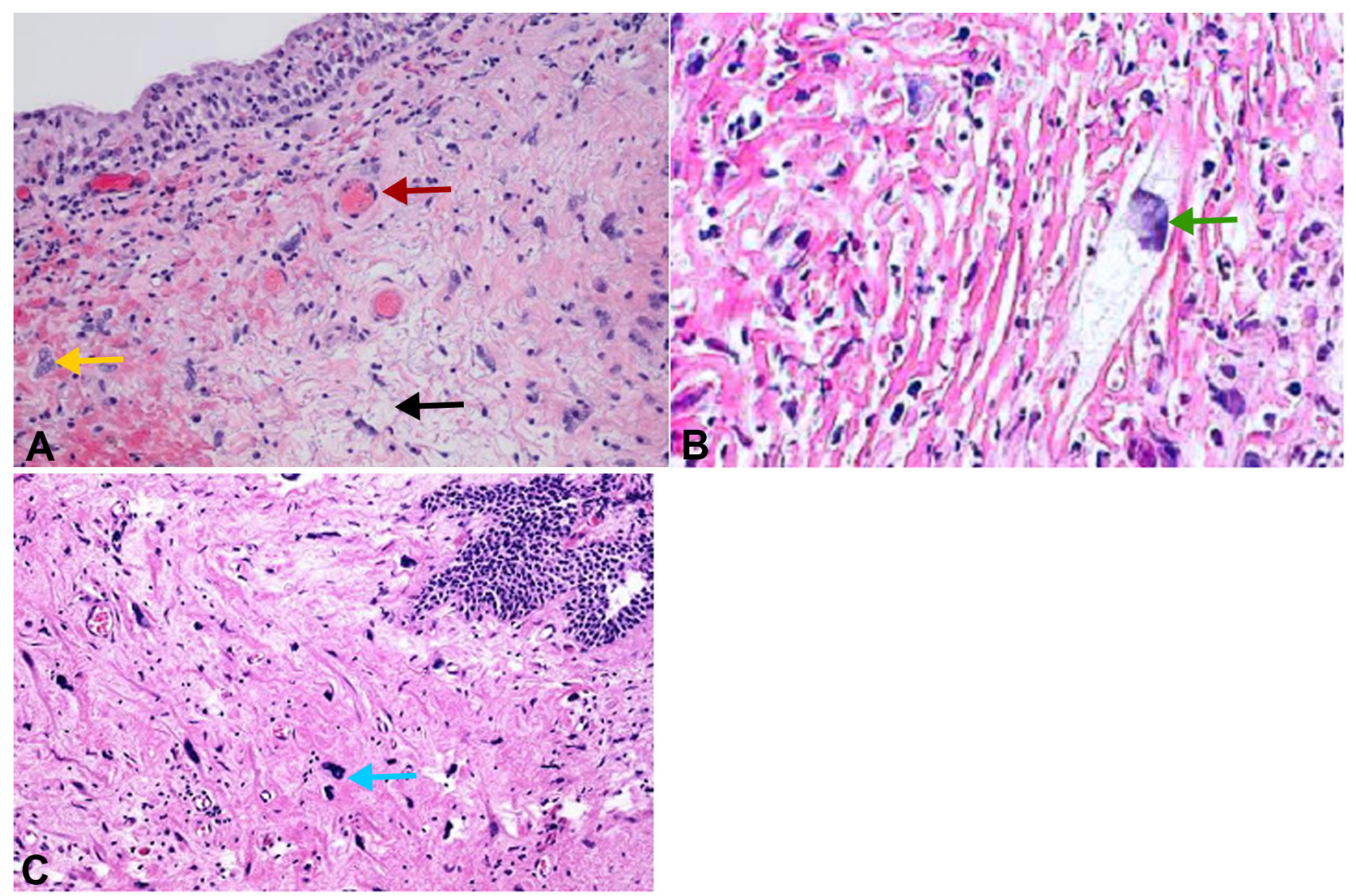

Figure 7. Histopathology of the necrosed bladder wall. A: Chronic radiation induced changes with fibrosis and cytological atypia (H and E, 100x); B: Enlarged nuclei with cystoplasmic vacuoles seen after radiation therapy (H and E, 100x); C: Marked nuclear atypia with necrotic background seen after radiation therapy (H and E, 40x). Red arrow: Fibrosis of blood vessels; Yellow arrow: Cytological atypia; Black arrow: Fibrinoid necrosis; Green arrow: Enlarged nuclei with cystoplasmic vacuoles; Blue arow: Marked nuclear atypia with necrotic background. 

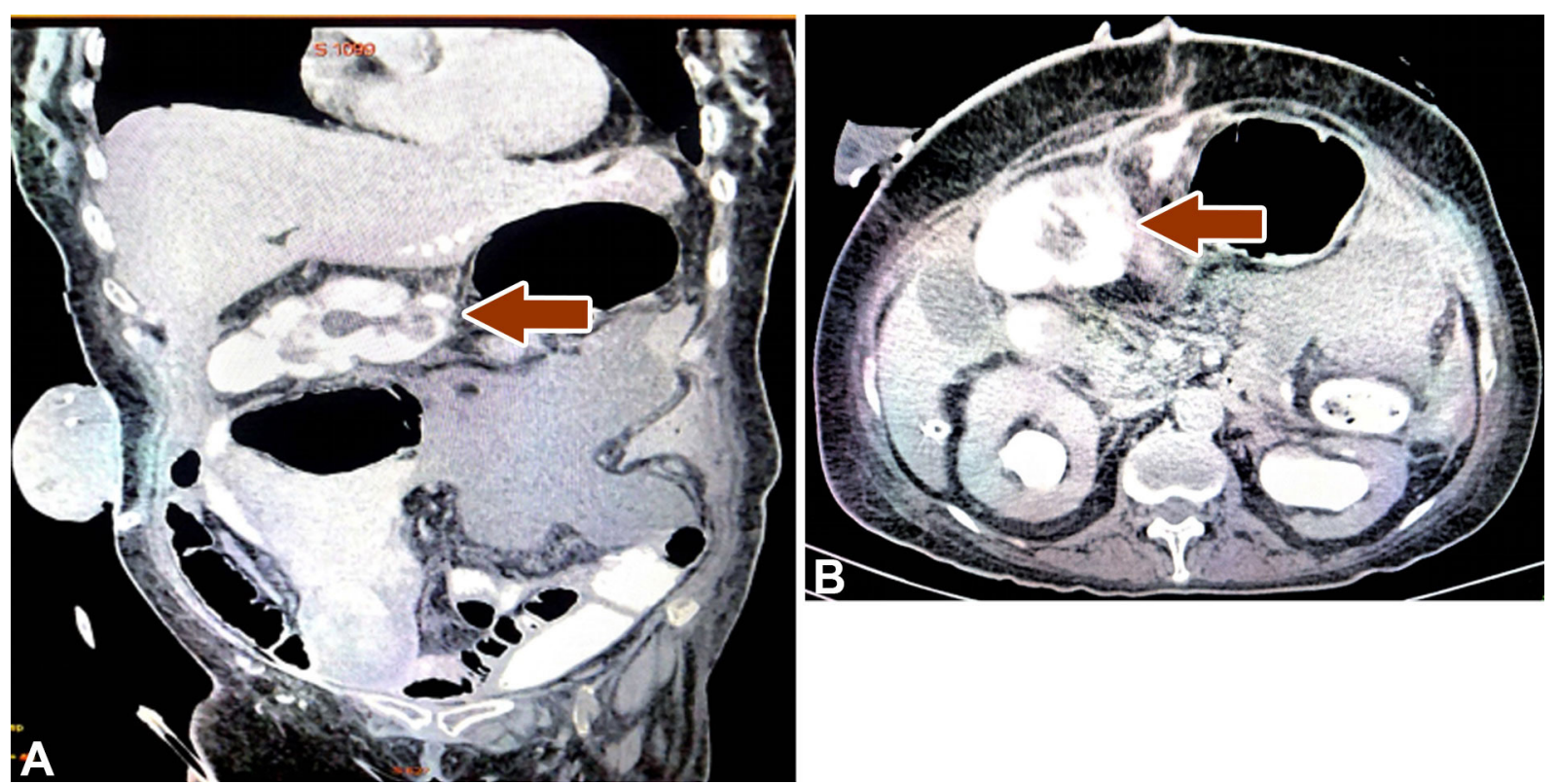

Figure 9. CECT Abdomen showing contrast in the sigmoid conduit. A: CECT abdomen coronal view shows contrast in the transverse conduit with left ureter draining into the transverse colon; B: CECT Abdomen axial view shows contrast in the sigmoid conduit with good drainage of the both kidneys.

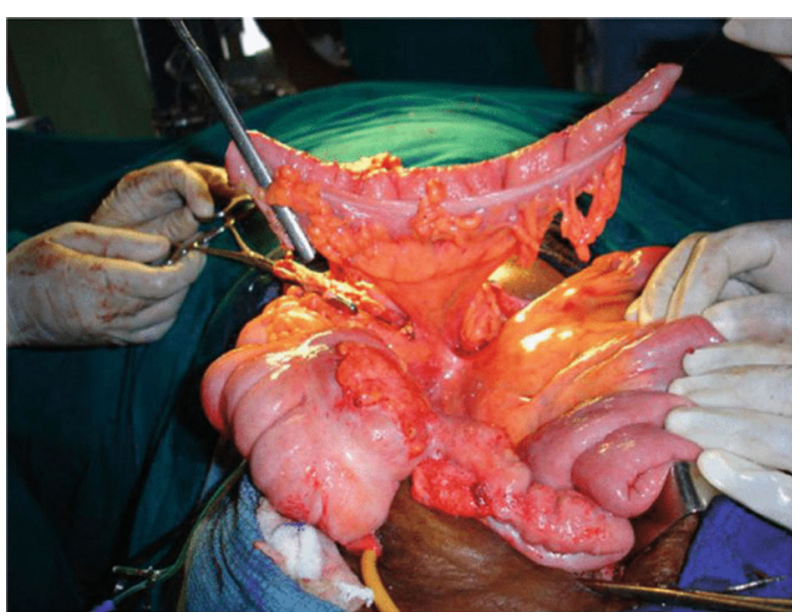

Figure 8. Shows the transverse colon isolated and fashioned as conduit.

in addition to surgery may also be indicated for patients with particular risk factors (e.g., high-grade tumour, lymphovascular space involvement, positive margins, multiple positive nodes). Optimal RT consists of EBRT and intracavitary high dose rateBT for a combined dose of $80-90$ Gy [7]. Overall, $53 \%$ of women receive RT within six months of diagnosis [10].

The posterior bladder and insertion point of the ureters lie directly anterior to the cervix, making these areas most susceptible to injury. The most common major urinary AEs (grade 3 or above) are ureteral stenosis, vesicovaginal fistula, and hematuria.11 The risk of developing major urinary AEs is greatest in the first three years following treatment $(0.7 \%$ per year $)$ but there remains a constant actuarial risk of $0.25 \%$ per year for at least 25 years [11], [12]. The delay between RT and AEs can be substantial; ureteral stricture has been observed 29 years after RT for cervical cancer, and spontaneous bladder rupture has been reported as late as 30 years after [13]. Risk of increasingly severe AEs following RT is significantly associated with larger doses of radiation and the number of treatments [11].

\section{Conclusion}

Radiation-induced injury of the urinary tract is a complex and debilitating complication and can lead to significant morbidity for the patient. This case is a rare example of high-grade AEs which occurred 8 yrs after RT in a known case of carcinoma of the cervix. An improved understanding of RT AEs in general and late AEs, in particular, should aid patient-provider discussions of the risks and benefits of their treatment options and highlight areas for future research into ways to minimize these unintended consequences of care. An astute Urologist must be vigilant in expecting, recognising and managing EBRT induced urological complications in patients with pelvic malignancies especially complete urinary bladder necrosis although it's a very rare case scenario.

\section{Acknowledgements}

We extend our sincere thanks to the patient who participated in the study.

\section{Ethical policy}

Approval was taken from institutional ethical committee. The study was performed in accordance with the Declaration of Helsinki. Patients gave their informed consent for their participation.

\section{Author contributions}

Conception and design of study: Mallikarjuna Reddy ;

Acquisition of data: Karthikesh Omkaram, Ershad Hussain Galeti 
Analysis and/or interpretation of data: Karthikesh Omkaram, Ershad Hussain Galeti, Vedamurthy Reddy;

Drafting the manuscript: Karthikesh Omkaram, Ershad Hussain Galeti, Vedamurthy Reddy, Bhanu Teja Reddy, Ayesha Galeti;

Revising the manuscript critically for important intellectual content: Mallikarjuna Reddy, Vedamurthy Reddy.

\section{Competing interests}

No conflict of interest.

\section{Funding}

None.

\section{Informed consent}

Written informed consent was obtained from the patient for publication.

\section{Ethical Approval}

Approved by the institutional ethical and research committee.

\section{References}

1. Cancer Facts \& Figures 2009. American Cancer Society; Atlanta: 2009.

2. Jonathan D, Tward JD, Christopher J, Anker CJ, et al. Radiation Therapy and Skin Cancer. In Natanasabapathi G. Modern Practices in Radiation Therapy. InTeched. 2012:207-246.

3. Elliott SP, Jarosek SA, Virnig BA. Unpublished analysis of SEER public use file. 1992-2006.

4. Ballek NK, Gonzalez CM. Reconstruction of radiation-induced injuries of the lower urinary tract. Urol Clin North Am 2013; 40: 407-419.

5. Bolus NE. Basic review of radiation biology and terminology. J Nucl Med Technol 2001; 29: 67-73; test 76-77.

6. Maier U, Ehrenbock PM, Hofbauer J. Late urological complications and malignancies after curative radiotherapy for gynecological carcinomas: a retrospective analysis of 10,709 patients. J Urol. 1997; 158: 814-817.

7. Hermans TJ, Delaere KP, Mens JW, Paffen ML. Blaasnecrose na radiotherapie voor cervixcarcinoom [Necrotic bladder following radiotherapy for cervical carcinoma]. Ned Tijdschr Geneeskd. 2012; 155(35): A4951.

8. American Cancer Society. Cancer Facts \& Figures 2013. Atlanta: American Cancer Society; 2013.

9. Colombo N, Carinelli S, Colombo A, et al. Cervical cancer: ESMO Clinical Practice Guidelines for diagnosis, treatment and follow-up. Ann Oncol 2012;23 Suppl 7: vii27-32.

10. Elliott SP, Jarosek SA, Virnig BA. Unpublished analysis of SEER public use file. 1992-2006.

11. Eifel PJ, Levenback C, Wharton JT, et al. Time course and incidence of late complications in patients treated with radiation therapy for FIGO stage IB carcinoma of the uterine cervix. Int J Radiat Oncol Biol Phys 1995; 32: 1289-1300.

12. Pötter R, Georg P, Dimopoulos JC, et al. Clinical outcome of protocol based image (MRI) guided adaptive brachytherapy combined with $3 \mathrm{D}$ conformal radiotherapy with or without chemotherapy in patients with locally advanced cervical cancer. Radiother Oncol 2011; 100: 116-123.

13. Nishimura T, Suzuki K, Iijima M, et al. Spontaneous rupture of bladder diverticulum after postoperative radiotherapy for carcinoma of the uterine cervix: a case report. Radiat Med 2000; 18: 261-265. 